\title{
Changes in extreme regional sea surface height due to an abrupt weakening of the Atlantic meridional overturning circulation
}

\author{
S.-E. Brunnabend ${ }^{1}$, H. A. Dijkstra ${ }^{1}$, M. A. Kliphuis ${ }^{1}$, B. van Werkhoven ${ }^{2}$, H. E. Bal ${ }^{2}$, F. Seinstra ${ }^{2}$ J. Maassen $^{3}$, and \\ M. van Meersbergen ${ }^{3}$ \\ ${ }^{1}$ Institute of Marine and Atmospheric Research Utrecht, Utrecht University, Princetonplein 5, \\ 3584 CC Utrecht, the Netherlands \\ ${ }^{2}$ Department of Computer Science, VU University Amsterdam, 1081 HV Amsterdam, the Netherlands \\ ${ }^{3}$ Netherlands eScience Center, 1098 XG Amsterdam, the Netherlands \\ Correspondence to: S.-E. Brunnabend (s.h.brunnabend@uu.nl)
}

Received: 13 March 2014 - Published in Ocean Sci. Discuss.: 30 April 2014

Revised: 12 August 2014 - Accepted: 26 September 2014 - Published: 7 November 2014

\begin{abstract}
As an extreme scenario of dynamical sea level changes, regional sea surface height (SSH) changes that occur in the North Atlantic due to an abrupt weakening of the Atlantic meridional overturning circulation (AMOC) are simulated. Two versions of the same ocean-only model are used to study the effect of ocean model resolution on these SSH changes: a high-resolution (HR) strongly eddying version and a low-resolution (LR) version in which the effect of eddies is parameterised. The weakening of the AMOC is induced in both model versions by applying strong freshwater perturbations around Greenland. A rapid decrease of the AMOC in the HR version induces much shorter return times of several specific regional and coastal extremes in North Atlantic SSH than in the LR version. This effect is caused by a change in main eddy pathways associated with a change in separation latitude of the Gulf Stream.
\end{abstract}

\section{Introduction}

The global mean rate of sea level rise over the twentieth century, as deduced from tide gauges, is about $1.7 \pm 0.5 \mathrm{~mm} \mathrm{yr}^{-1}$ (Bindoff et al., 2007; Church and White, 2011). However, regional sea level changes have been very inhomogeneous over this period and are affected by changes in atmospheric wind stresses, and surface heat and freshwater fluxes (Ishii et al., 2003; Volkov et al., 2003; Antonov et al., 2005; Bindoff et al., 2007; Berge-Nguyen et al., 2008; Church et al., 2008; Woodworth et al., 2011a). Hence, regional sea level change is often associated with variations in ocean circulation (Landerer et al., 2007; Levermann et al., 2005; Flückiger et al., 2006; Stammer, 2008; Stammer et al., 2011; Lorbacher et al., 2010; Hu et al., 2011). Changes in the amount of water in the oceans (barystatic), as well as changes in land water mass distribution, and their gravitational, elastic and rotational effects (changes in the static equilibrium) may also affect regional sea level (Farrell and Clark, 1976; Clark et al., 1978; Mitrovica et al., 2001, 2011; Kopp et al., 2010).

Changes in regional extreme sea levels have been related mostly to changes in the mean sea level, storm surges and wind set-up (Marcos et al., 2009; Lowe et al., 2010; Woodworth et al., 2011b). However, in a recent study of water levels from tide gauges, Merrifield et al. (2013) identified, apart from tidal and seasonal components, non-tidal residual components as an important contribution to annual maximum water levels. Such non-tidal residuals can result from highfrequency storms and processes on sub-annual timescales. Firing and Merrifield (2004) indicated, through an example near Hawaii in September 2003, that mesoscale eddies may have an important influence on extreme sea levels. They describe an eddy that gave rise to extreme sea levels as it coincided with high sea levels in both seasonal and longer (decadal) timescale components.

Apart from sea level changes due to gradual background climate changes there is the potential for more rapid and extreme sea level changes due to the sensitivity of the Atlantic meridional overturning circulation (AMOC) to freshwater anomalies (Yin et al., 2009; Srokosz et al., 2012). In this case, 
the large-scale changes in the ocean circulation may lead to large background sea level changes in a few decades. These have to be added to the sea level changes, which are caused by the many other processes on the regional scale.

One of the sources of freshwater input is the mass loss of the Greenland Ice Sheet (GrIS) which is at the moment estimated to be about $0.01 \mathrm{~Sv}$ (Mernild et al., 2010). A scenario where GrIS freshwater might modify the AMOC has been considered in different ocean-climate models. These models mostly employ a freshwater inflow of $0.1 \mathrm{~Sv}$ and a horizontal resolution of about $1.0^{\circ}$ such that the effect of ocean eddies is parameterised. In most of these non-eddying ocean-climate models, the AMOC weakens in response to this freshwater input. This weakening has a strong dependence on the model resolution, the amount of freshwater inflow and on the region where the freshwater is introduced into the ocean (Gerdes et al., 2006; Stouffer et al., 2006; Stammer, 2008; Kopp et al., 2010; Hu et al., 2011; Stammer et al., 2011; Brunnabend et al., 2012).

These model studies have indicated that the freshening and the change in the AMOC affect regional sea levels in the North Atlantic (Levermann et al., 2005; Flückiger et al., 2006). On multidecadal timescales, the freshwater from the GrIS leads to a sea level response mainly in the North Atlantic. Stammer (2008), using the MITgcm (MIT general circulation model) (Marshall et al., 1997), found a decreasing sea level in the subpolar North Atlantic. He attributed this depression to cold water anomalies, an accelerated subpolar gyre and a slowdown of the sub-tropical gyre. A similar sea level response is also visible in the study of Stammer et al. (2011), where a coupled ocean-atmosphere model is used. The study by $\mathrm{Hu}$ et al. (2011) estimated the potential of mass loss of the GrIS under different climate scenarios using the climate system model version 3 (CCSM3, Collins et al., 2006). The resulting dynamic sea level change does not show this significant signal. Only a slightly negative signal south of Iceland is visible, which disappears under a warmer background climate. The simulations of Wang et al. (2012) and Brunnabend et al. (2012) were performed using the finite element sea-ice ocean model (FESOM, Sidorenko et al., 2011). With a more realistic GrIS freshwater perturbation (Brunnabend et al., 2012), only a reduced sea level increase is visible in the subpolar North Atlantic.

Recently, a hosing simulation was performed with a strongly eddying ocean model. In Weijer et al. (2012), the transient multidecadal timescale response of the AMOC due to $0.1 \mathrm{~Sv}$ of freshwater inflow at the Greenland coast was determined using the parallel ocean program (POP) model. Both the magnitude of the response as well as the mechanisms of AMOC decline are different in the strongly eddying model than in the non-eddying version of the POP (Den Toom et al., 2014). The low-resolution model results show a change of the net freshwater advection that is consistent with the salt advection feedback. However, for the eddy-resolving model, the net freshwater advection into the Atlantic basin appears to be unaffected, despite the significant change in the large-scale velocity structure.

The main aim of this study is to investigate the impact of an abrupt AMOC decline due to GrIS freshwater input on extremes in regional sea surface height in the North Atlantic. The interesting aspect is that a large change in the AMOC potentially can lead to changes in the spatio-temporal properties of the eddy field and hence may affect regional extremes in sea level. In Sect. 2, the methods applied and the simulations performed are discussed. Using a similar approach as in Weijer et al. (2012) and Den Toom et al. (2014), we compare the AMOC and sea surface height responses to GrIS freshwater perturbations in both a non-eddying and a strongly eddying version of the same ocean model (POP) in Sect. 3. Extreme value theory is applied on sea surface height data (regional and coastal) to determine changes in extremes associated with the AMOC changes (and freshening) in the North Atlantic and the processes causing these changes are considered. A summary and discussion is provided in Sect. 4.

\section{Model and simulations}

Simulations were performed using the global Los Alamos parallel ocean program (POP) (Maltrud et al., 2008), forced by monthly atmospheric climatology data (CORE I; Large and Yeager, 2004). The high-resolution model, here referred to as HR, has a spatial resolution of $0.1^{\circ}$ horizontally and has 42 depth levels. The horizontal grid allows for the representation of eddies and detailed boundary currents, such as an adequate separation behaviour of the Gulf Stream (Maltrud et al., 2008). In the low-resolution version of the POP model, here referred to as the LR version, the grid has a horizontal resolution of $1.0^{\circ}$ and has 40 depth levels and the effects of eddies are parameterised. As described in Weijer et al. (2012), mixed boundary conditions are used in both model versions where the prescribed freshwater flux is derived from an earlier restoring simulation (hence, in the simulations discussed below, there is no salinity restoring applied). Further details about the spin-up, forcing and simulations with both versions of the POP model can be found in the Supplement of Weijer et al. (2012).

In both LR and HR versions, a prognostic implicit freesurface formulation is used where the sea surface height $\eta$ is solved from a linearised free-surface model. Following Landerer et al. (2007), we will refer to $\eta$ as the dynamic sea surface height (SSH). Since the freshwater forcing is represented as a virtual salt flux, no net global changes in the precipitation-evaporation and river runoff can occur and hence no barystatic changes are represented. The variations in SSH can be decomposed into contributions from bottom pressure changes and steric height variations (the barometric correction is zero). The spatially homogeneous (but time-dependent) global steric contribution can be determined from the ocean model output in a post-processing 
step (Greatbatch, 1994). However, the global mean steric contribution originating from additional freshwater inflow around Greenland appears to be 1 order of magnitude smaller than the corresponding global mean mass contribution $\left(0.3 \mathrm{~mm} \mathrm{yr}^{-1}\right.$ per $\left.100 \mathrm{Gt} \mathrm{yr}^{-1}\right)$. (Brunnabend et al., 2012). Hence, it is not considered here.

Apart from a control simulation, with no additional freshwater inflow around Greenland and hence with constant salt content in the ocean, two 50-year simulations are performed with both the LR and HR model versions. In the first simulation, an additional $0.1 \mathrm{~Sv}$ is added around Greenland and in the second simulation $0.5 \mathrm{~Sv}$ is added. The freshwater inflow around Greenland has a seasonal dependence with maximum amplitudes in July. The spatial distribution of the freshwater input, as shown in Fig. 1 of Weijer et al. (2012), is based on observations of calving and runoff derived by Rignot and Kanagaratnam (2006). This distribution includes a high rate of freshwater inflow near southeast and west Greenland and no inflow in the southwest. Lower rates are located at the northern and northeast coast of Greenland.

In the results below, SSH changes are computed by taking the difference (below indicated by SSHP) between a model simulation including the additional freshwater inflow and the control simulation. With this method, only the SSH changes that are caused by the reduced AMOC are considered and the variations in SSH that occur without the hosing included in the model simulation are not included. Before analysis, the data from the LR and HR simulations are interpolated to a regular $0.4^{\circ}$ horizontal longitude-latitude grid.

To analyse regional extremes in short-term SSHP, monthly mean SSHP in three different regions in the North Atlantic is analysed (cf. Fig. 5). These regions are chosen because they represent areas of major change in SSHP extremes. As extremes in sea level for area-averaged quantities are investigated, the interpolation to a regular grid has no influence on the results.

Extremes in the monthly mean SSHP that are induced by short-term SSHP variations are investigated using extreme value theory (Coles, 2001). First, we filter out the long-term SSHP signal at each grid point of a region using a high-pass filter with a cutoff frequency of 18 months. Then the maximum SSHP value (over the specific region) is determined for each month. The extreme SSHP values obtained over the first 10 model years (model years 1-10) are then compared with those over the last decade (model years 41-50) by determining parameters in the generalised extreme-value (GEV) distribution based on 120 data points (months). Parameters are fitted using the maximum-likelihood method of the GEV distribution (Coles, 2001)

$G(y)=\exp \left\{-\left[1+\xi\left(\frac{y-\mu}{\sigma}\right)\right]^{-\frac{1}{\xi}}\right\}$,

where $\mu, \sigma$ and $\xi$ are the location, scale and shape parameter, respectively; they characterise the behaviour of the SSHP (a)
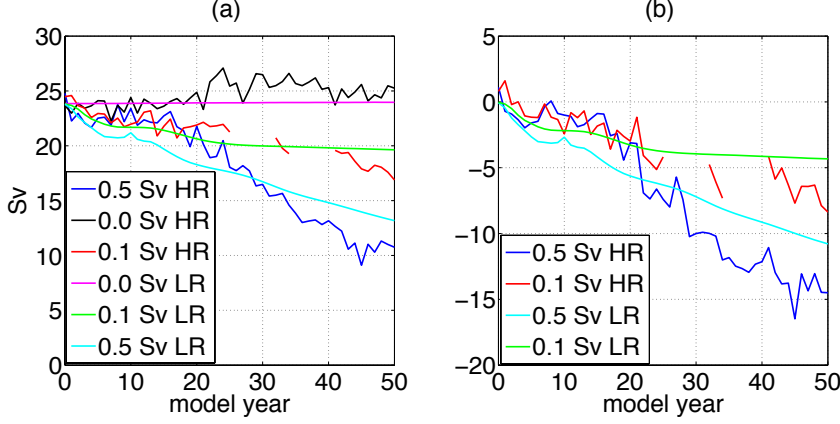

Figure 1. (a) Strength of the Atlantic meridional overturning circulation (AMOC) at $35^{\circ} \mathrm{N}$ for the HR control simulation (black), the LR control simulation (magenta), the $0.1 \mathrm{~Sv}$ HR simulation (red, the gaps are due to missing data), the $0.5 \mathrm{~Sv}$ HR simulation (blue) and the LR 0.5 Sv simulation (light blue). (b) AMOC anomalies (with respect to the control simulation) of the different perturbed simulations with the same colour coding as in (a).
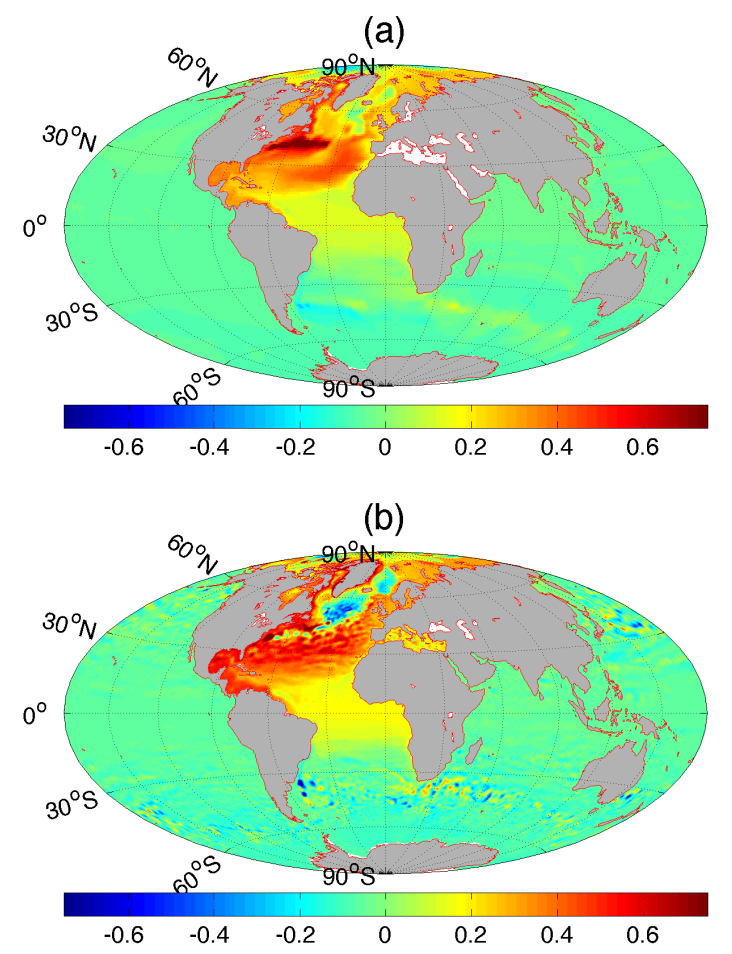

Figure 2. (a) Change in SSH (hosing - control) after 50 years due to $0.5 \mathrm{~Sv}$ of freshwater inflow around Greenland in the LR model. (b) Same as (a) but for the HR model.

extremes. $G(y)$ is the fitted generalised distribution function to the GEV distribution of the monthly maximum values of the region and is defined for $y$ such that $1+\xi\left(\frac{y-\mu}{\sigma}\right)>0$ and $\xi \neq 0$. Results are interpreted as return level $z_{\mathrm{p}}$ and return period $T$ (Coles, 2001).

$z_{\mathrm{p}}=\mu-\frac{\sigma}{\xi}\left\{1-\left[-\log \left(1-\frac{1}{T}\right)\right]^{-\xi}\right\}$ 

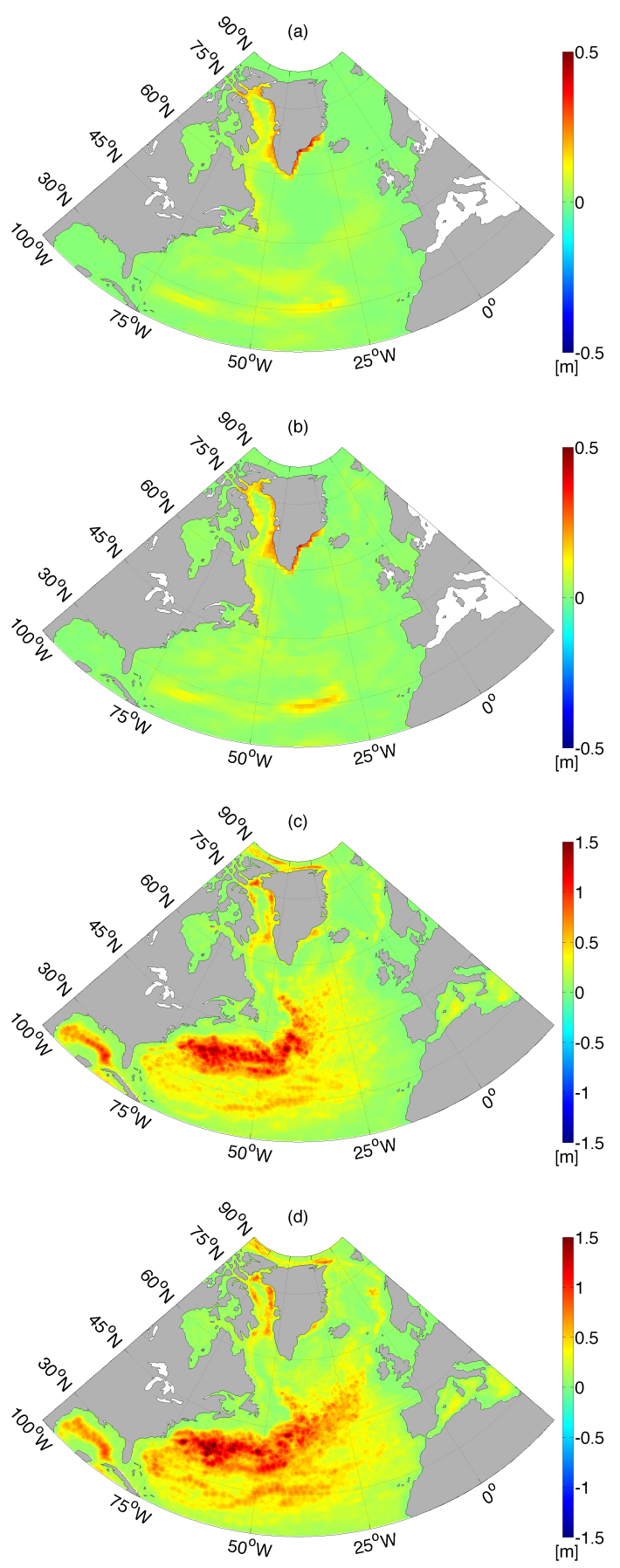

Figure 3. Maximum of monthly SSHP (hosing - control) $0.5 \mathrm{~Sv}$ GrIS perturbation of the first $10(\mathbf{a}, \mathbf{c})$ and last $10(\mathbf{b}, \mathbf{d})$ model years, for the LR (a, b) and HR (c, d) model simulations.

The changes in coastal SSHP extremes are computed by identifying the maximum SSHP of every month from daily mean data at four coastal locations. Before the changes in coastal SSHP extremes are computed, the long-term signal has been removed from the daily time series to consider only short-term variations, i.e. those caused by high-frequency
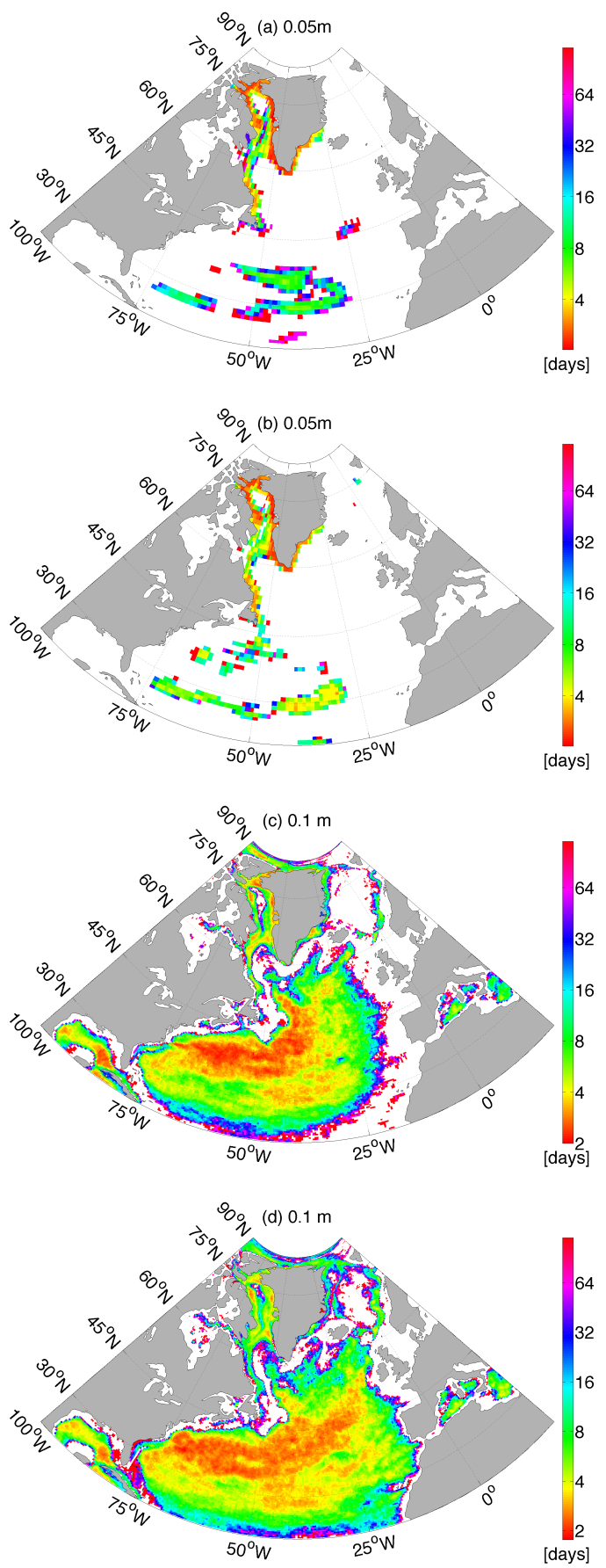

Figure 4. Average return period for a $0.05 \mathrm{~m}$ anomaly (SSHP (hosing - control) for the $0.5 \mathrm{~Sv}$ LR simulation) of the first (a) and last (b) 10 years, and average return period for a $0.1 \mathrm{~m}$ anomaly (SSHP (hosing - control) $0.5 \mathrm{~Sv}$ HR simulation) of the first (c) and last (d) 10 years. In the white areas the specific anomaly has not been reached during the time period. 


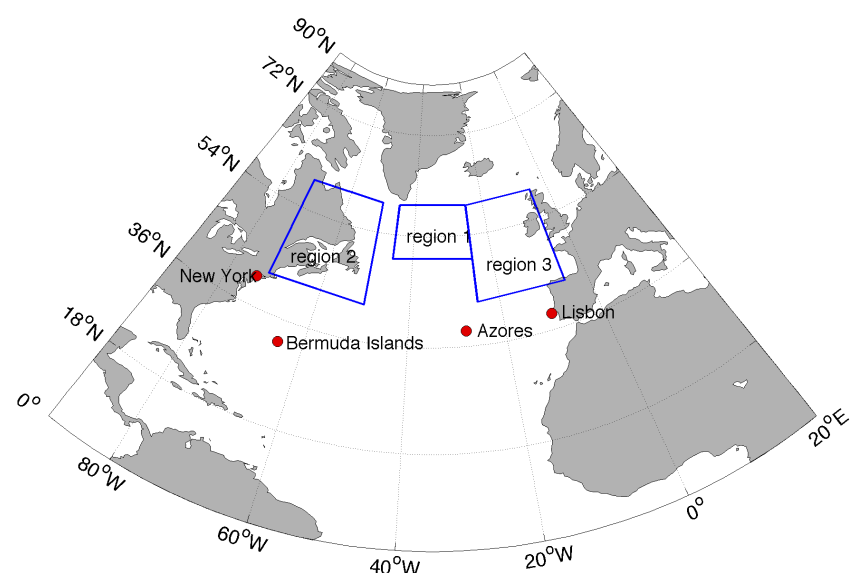

Figure 5. Location of three areas and four coastal positions chosen to investigate extreme regional sea level changes. (a) region 1 (0.1 Sv)

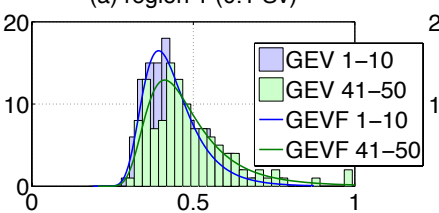

(b) region $2(0.1 \mathrm{~Sv})$

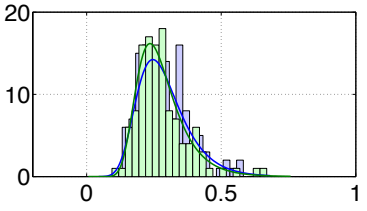

(c) region $3(0.1 \mathrm{~Sv})$

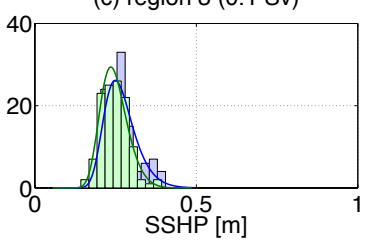

(d) region 1 (0.5 Sv)

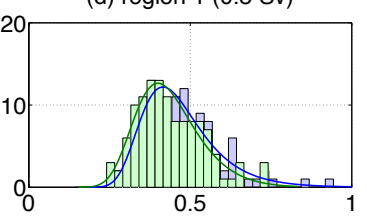

(e) region $2(0.5 \mathrm{~Sv})$

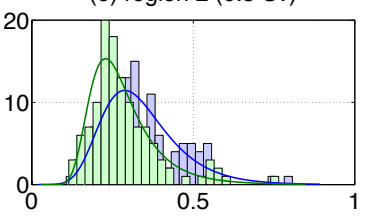

(f) region $3(0.5 \mathrm{~Sv})$

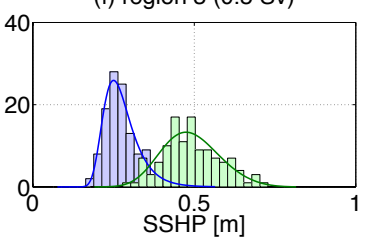

Figure 6. Generalised extreme-value (GEV) distribution and the corresponding fitted distributions of the maximum SSHP changes in the the regions shown in Fig. 5. (a-c) GEV plots for the $0.1 \mathrm{~Sv}$ HR simulation. (d-f) GEV plots for the $0.5 \mathrm{~Sv}$ HR simulation.

variations in the flow, for example due to eddies. The return times of extremes in SSHP of the first 10 years of the model simulation are next compared to those of the last 10 years. When considering coastal SSH extremes, locations are used that are (on the $0.4^{\circ}$ grid) at the same point as in the $0.1^{\circ}$ grid to make sure no systematic inflation of extremes occurs.

\section{Results}

The maximum of the annual mean $\mathrm{AMOC}$ at $35^{\circ} \mathrm{N}$ (the approximate latitude of the overall maximum) for the LR and

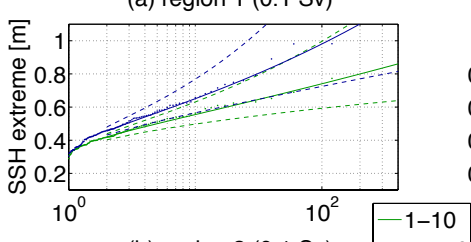

(b) region $2(0.1 \mathrm{~Sv}) \quad-41-50$

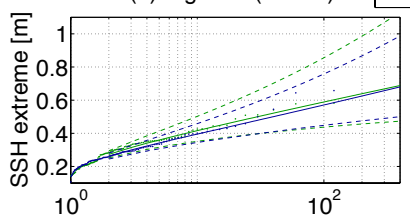

(c) region $3(0.1 \mathrm{~Sv})$

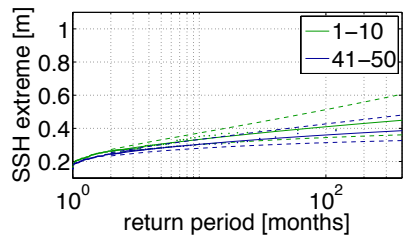

(a) region $1(0.1 \mathrm{~Sv})$ (d) region 1 (0.5 Sv)

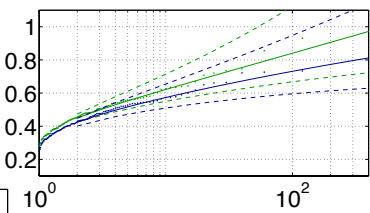

(e) region 2 (0.5 Sv)

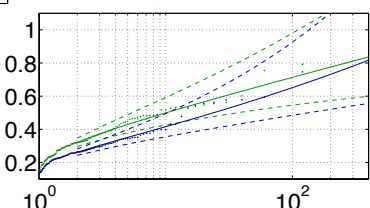

(f) region $3(0.5 \mathrm{~Sv})$

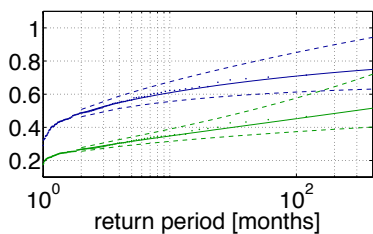

Figure 7. Generalised extreme-value (GEV) distribution fits to monthly maximum SSHP changes in the different regions. (a-c) GEV plots for the $0.1 \mathrm{~Sv}$ HR simulation. (d-f) GEV plots for the $0.5 \mathrm{~Sv}$ HR simulation. The extreme values are plotted as a function of return times using 10 years of data at the beginning of the simulation (green: years 1-10) and for a similar period at the end of the simulation (blue: 41-50). The dashed curves indicate the $95 \%$ confidence interval corresponding to the GEV fit. The longterm signal is filtered out before determining the extreme values.

HR control simulations, the LR and HR $0.1 \mathrm{~Sv}$ simulation and the HR and LR 0.5 Sv simulations are plotted in Fig. 1a. The strength of the AMOC at $35^{\circ} \mathrm{N}$ for the HR $0.0 \mathrm{~Sv}$ simulation slightly increases and equilibrates to an annual average of about $25 \mathrm{~Sv}$ in 50 years. For both HR 0.1 and $0.5 \mathrm{~Sv}$ simulations, the strength of the AMOC decreases to values of about 18 and $11 \mathrm{~Sv}$, respectively, at year 50. The gaps in the time series of the HR $0.1 \mathrm{~Sv}$ simulations are due to missing data values. For details please refer to the Supplement of Weijer et al. (2012). The effect of the extra freshwater perturbation near Greenland can be more explicitly seen in Fig. 1b, where the differences to the control simulation are plotted. For the HR $0.5 \mathrm{~Sv}$ case, a reduction of about $14 \mathrm{~Sv}$ occurs over 50 years of simulation. The pattern of the AMOC remains the same during its weakening and there is no collapse to a different equilibrium (Den Toom et al., 2014). The overturning cell weakens due to the additional freshwater input near Greenland and the reverse bottom cell slightly strengthens. The same holds for the LR $0.5 \mathrm{~Sv}$ simulation results (Den Toom et al., 2014).

\subsection{Sea surface height changes}

The pattern and amplitude of the near-equilibrium (annual mean) SSH at the start of the freshwater perturbation for 
(a) region $1(0.1 \mathrm{~Sv})$

(b) region $2(0.1 \mathrm{~Sv})$

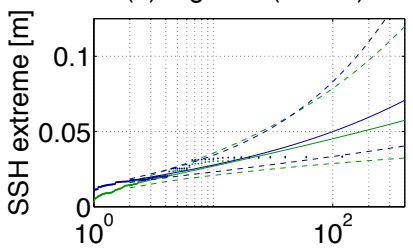

(c) region $3(0.1 \mathrm{~Sv})$

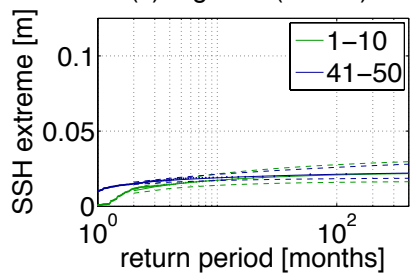

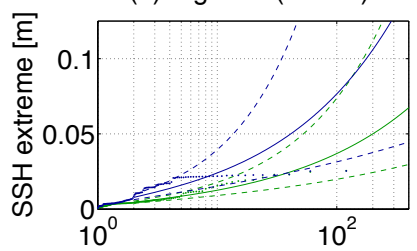

(d) region $1(0.5 \mathrm{~Sv})$

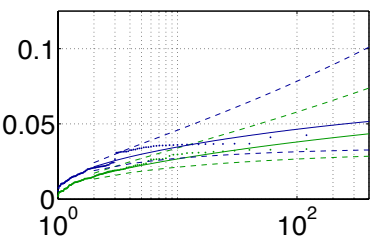

(e) region $2(0.5 \mathrm{~Sv})$

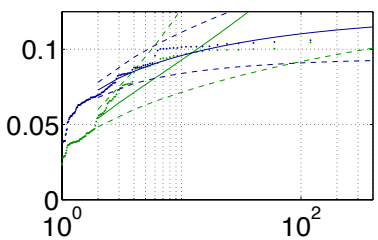

(f) region $3(0.5 \mathrm{~Sv})$

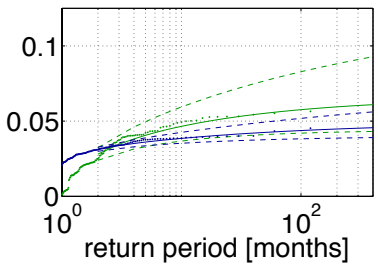

Figure 8. Generalised extreme-value (GEV) distribution fits to monthly maximum SSHP changes in the different regions; (a-c) GEV plots for the 0.1 Sv LR simulation and (d-f) GEV plots for the $0.5 \mathrm{~Sv}$ LR simulation. The extreme values are plotted as a function of return times using 10 years of data at the beginning of the simulation (green: years 1-10) and for a similar period at the end of the simulation (blue: 41-50). The dashed curves indicate the $95 \%$ confidence interval corresponding to the GEV fit. The lowfrequency signal is filtered out before determining the extreme values.

the LR and HR configurations compare well with those in other coarse-resolution models (e.g. Landerer et al., 2007). The SSH pattern of the HR configuration compares very well with that of the CMDT-RIO03 model of dynamic topography (Rio and Hernandez, 2004; Landerer et al., 2007) having more detailed spatial variations in the western boundary current regions than the SSH pattern of the LR configuration. Over 50 years, modelled SSH for the $0.5 \mathrm{~Sv}$ simulation mainly changes in the North Atlantic, as shown in Fig. 2a (LR) and Fig. 2b (HR). Although the patterns are overall similar, Fig. $2 \mathrm{~b}$ provides much more spatial detail as it also includes the eddy-induced small-scale SSH changes. The difference in SSH change between Fig. 1a and b is particularly striking in the subpolar gyre. In the HR simulation, a SSH decrease occurs whereas a small SSH increase is found in the LR simulation.

In general, the temporal evolution of the pattern of SSH change in the North Atlantic caused by the additional freshwater agrees well with other studies (Stammer, 2008; Hu et al., 2011; Wang et al., 2012; Brunnabend et al., 2012). During the first years, SSH mainly changes in the area of

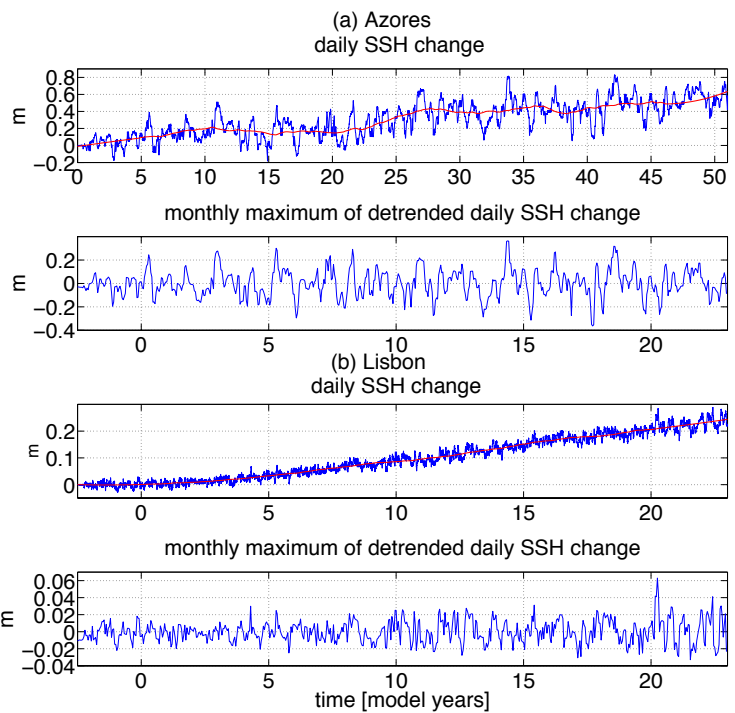

(c) New York

daily SSH change
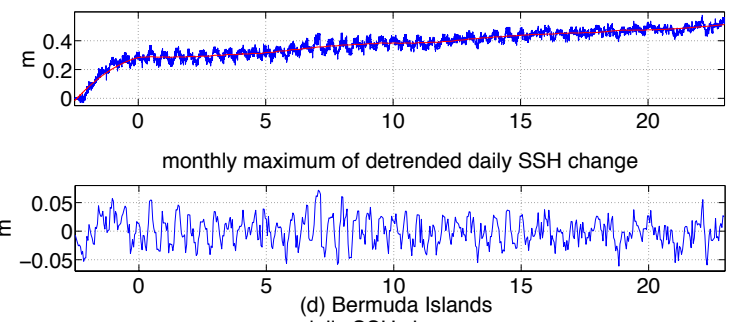
daily SSH change

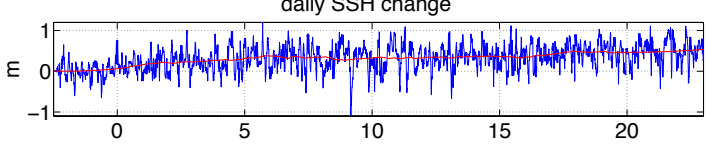

monthly maximum detrended daily $\mathrm{SSH}$ change

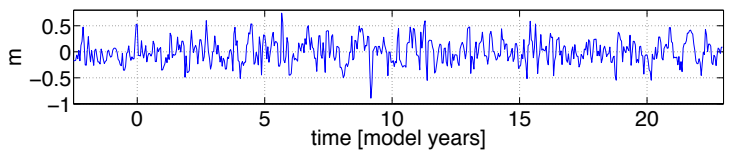

Figure 9. (a-d) Monthly maximum values of daily SSHP change at a coastal location (blue) with its long-term signal (red) and the monthly maximum of the high-pass-filtered (detrended) daily mean SSHP change. The locations considered are (a) Azores, (b) Lisbon, (c) New York and (d) Bermuda Islands.

the Labrador Sea and Baffin Bay. As freshwater is transported by the western boundary currents, SSH rises near the North American coast. In the following years the freshwater is transported eastward where it separates and distributes to the Arctic Ocean as well as to the equatorial Atlantic. The corresponding halo-steric expansion leads SSH to rise in the freshened regions. The main difference to the LR simulation is that in the HR simulation the freshwater anomaly is more homogeneous due to the mixing effect of the eddies. The model results show a similar positive mass redistributioninduced pattern in SSH change near the North American coast as previously shown by Yin et al. (2009). The steric 
(a) Azores (0.5 Sv)

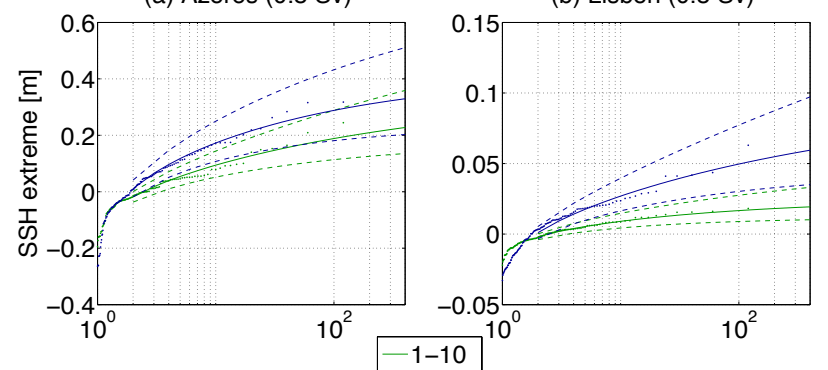

(c) New York (0.5 Sv) $-41-50$ (d) Bermuda Islands (0.5 Sv)
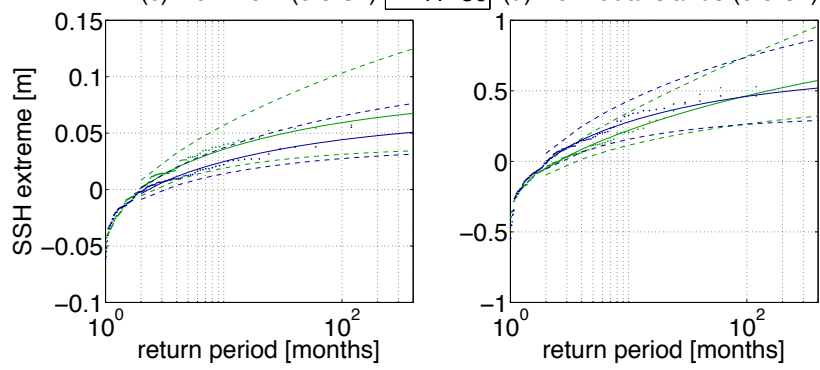

Figure 10. Generalised extreme-value (GEV) distribution fits to monthly maxima of detrended daily SSHP changes in the different coastal locations in the North Atlantic for the $0.5 \mathrm{~Sv}$ HR simulation. The extreme values are plotted as a function of return times using 10 years of data at the beginning of the simulation (green: years 110) and for a similar period at the end of the simulation (blue: 4150). The dashed curves indicate the $95 \%$ confidence interval corresponding to the GEV fit. The locations considered are (a) Azores, (b) Lisbon, (c) New York and (d) Bermuda Islands.

contribution differs from the study by Yin et al. (2009) due to the huge amount a freshwater inflow around Greenland applied in our simulations, which lead to a strong positive steric anomaly near the North American coast.

\subsection{Changes in sea surface height extremes}

To investigate regional changes in sea-level extremes that are caused by short-term variations, such as eddies, the maximum of the monthly mean SSHP of the first and last 10 years of the LR and HR $0.5 \mathrm{~Sv}$ simulations is computed. In the case of the LR simulation, the maximum monthly SSHP shows large-scale patterns and no obvious changes are visible as shown in Fig. 3a-b. In the case of the HR simulation, the resolved eddy fields lead to more patchy patterns most pronounced in the area of the Gulf Stream (Fig. 3cd). Main changes are located in the eastern North Atlantic where an increase in the maximum monthly SSHP is visible. In this region also the average return period for a $0.1 \mathrm{~m} \mathrm{SSHP}$ anomaly is increased (Fig. 4c-d). In addition, the subpolar gyre region shows slightly reduced average return times for a $0.1 \mathrm{~m}$ SSHP anomaly. In the western North Atlantic only small changes in the monthly maximum SSHP and in the average return period are visible for the HR simulation, but for the LR simulation variations in the average return period of a $0.05 \mathrm{~m}$ anomaly exist (Fig. 4a-b). For these reasons, the regions chosen are the subpolar gyre (region 1), and the western (region 2) and eastern (region 3) North Atlantic as shown in Fig. 5.

Figure 6 shows the GEV distribution and the corresponding fitted distributions of the HR simulations for the first and last 10 years. In the $0.1 \mathrm{~Sv}$ HR simulation the distributions remain similar. The SSHP extremes only of region 1 are slightly redistributed to higher values. Large redistributions are existing in region 2 and region 3 in the $0.5 \mathrm{HR}$ simulation. In region 2, the extreme values are decreased, whereas in region 3 extreme values are redistributed to higher SSHP extremes.

For the $0.1 \mathrm{~Sv}$ HR simulation, the return period of an extreme of $1 \mathrm{~m}$ in region 1 (subpolar gyre) decreases from being longer than 500 months to about 100 months (Fig. 7a). In region 2 (western Atlantic), the SSHP extreme remains similar in time as this region mainly undergoes a change in the mean SSHP (Fig. 7b). In region 3 (eastern Atlantic), the extreme corresponding to a 100-month return period decreases by about $5 \mathrm{~cm}$ (Fig. 7c). For the 0.5 GrIS perturbed HR simulation, the return periods in region 1 (subpolar gyre, Fig. 7d) decrease by more than $10 \mathrm{~cm}$ for a return period of 100 months. Region 2 also experiences a slight decrease in the return periods, but becomes more similar with longer return periods (Fig. 7e). In region 3, much larger extremes occur in the last 10 years. The extreme corresponding to a 100month return period increases by $0.25 \mathrm{~m}$ (Fig. 7f). All GEV fits are significant as they are well inside the $95 \%$ confidence intervals.

Due to the low resolution applied, the results for the $0.1 \mathrm{~Sv}$ and $0.5 \mathrm{~Sv}$ LR simulation (Fig. 8) show much smaller changes (only a few centimetres) in the extreme SSHP values. In addition, high uncertainties in return times appear in regions where monthly maximum SSHP changes exceed the $95 \%$ confidence intervals, i.e. in regions 1 (Fig. 8a) and 2 (Fig. 8b) of the $0.1 \mathrm{~Sv}$ LR simulation and in region 2 (Fig. 8e) of the $0.5 \mathrm{~Sv}$ LR simulation. In contrast to the HR results, we see that in regions where high return times are significant, e.g. region 3 (Fig. 8c) of the $0.1 \mathrm{~Sv}$ LR simulation and region 1 (Fig. 8d) and region 3 (Fig. 8f) of the $0.5 \mathrm{~Sv}$ LR simulation, the curves flatten for higher return times.

At four coastal locations (Azores, Lisbon, New York, and Bermuda Islands) daily SSH changes due to the freshwater perturbation around Greenland are plotted in Fig. 9. The long-term changes mainly result from the reduced salinity in these regions. At the coast near New York, SSHP shows a strong increase in the first 3 years which is caused by the reduced salinity near the east coast of North America during that time period. Near Lisbon, SSHP only slightly increases until the freshwater has actually arrived in this region after about 1 decade. The changes in coastal SSHP extremes are computed by identifying the maximum SSHP of every month from daily mean data at the four coastal locations. Before the changes in coastal SSHP extremes are computed, the 
(a)

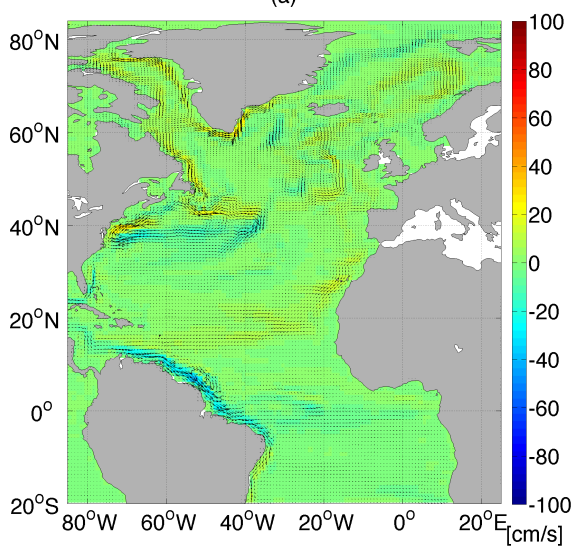

(c)

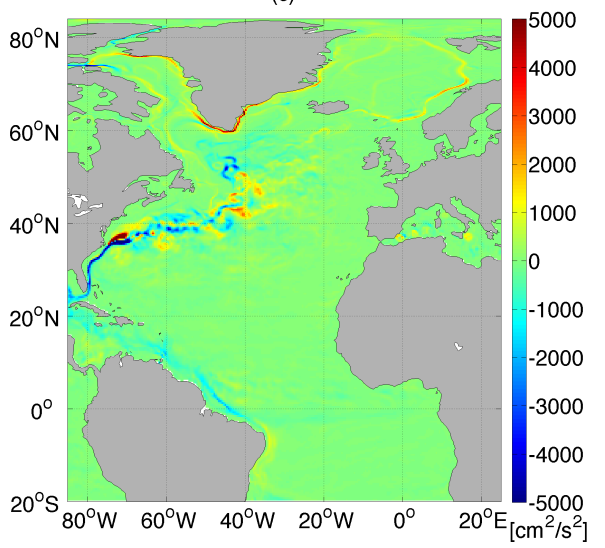

(b)

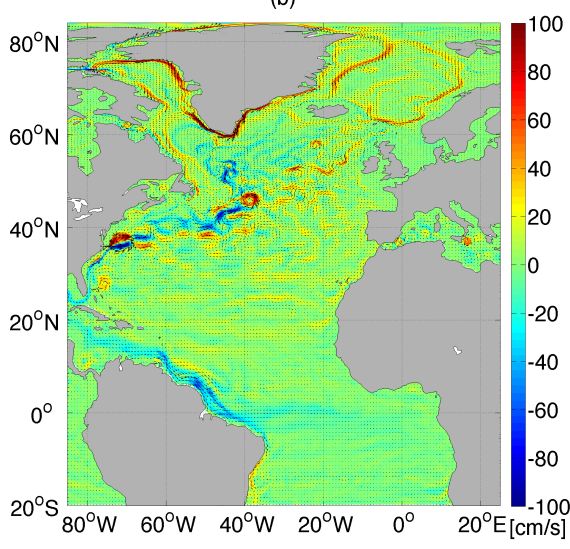

(d)

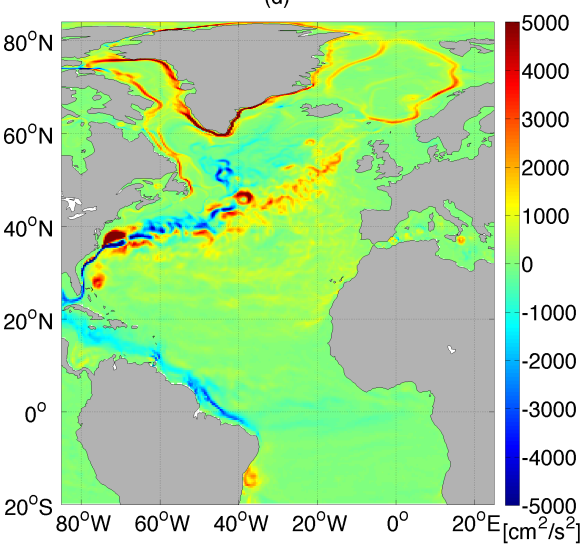

Figure 11. Changes of the horizontal velocity structure (in $\mathrm{cm} \mathrm{s}^{-1}$ ) caused by the $0.5 \mathrm{~Sv}$ perturbation after 50 model years (a) of the LR simulation and (b) of the HR simulation. Eddy kinetic energy (EKE) changes $\left(\mathrm{cm}^{2} \mathrm{~s}^{-2}\right)$ for the HR $0.1 \mathrm{~Sv}$ (c) and $0.5 \mathrm{~Sv}$ (d) after 50 years.

long-term signal has been removed from the daily time series to consider only short-term variations, i.e. those caused by high-frequency variations in the flow, for example due to eddies. At the European coast an increase in short-term extremes of about $10 \mathrm{~cm}$ (Azores) and $4 \mathrm{~cm}$ (Lisbon) for a return period of 100 months is visible (Fig. 10). The return times of short-term extremes remain similar at the Bermuda Islands, and the amplitude of the extremes for every return time near the coast near New York is only slightly decreased.

\subsection{Ocean flow changes}

To investigate the reasons for the changes in SSHP extremes in the LR and HR simulation, we analysed the changes in the modelled surface ocean circulation. The overall patterns of the annual mean surface horizontal velocity field in the North Atlantic for both LR and HR control simulations are similar in both versions of the model. However, the boundary layer currents are more narrow and the flow is much less spatially coherent in the HR version than in the LR version. The annual mean surface horizontal velocity field difference between the $0.5 \mathrm{~Sv}$ simulation and the control sim- ulation at year 50 is shown for the LR and HR simulations in Fig. 11a and b, respectively. Strong qualitative differences between the model results occur in the Gulf Stream region and the subpolar gyre. Changes in surface speeds are up to $1 \mathrm{~m} \mathrm{~s}^{-1}$ in the HR simulation while they are much smaller in the LR simulation.

The strength of the modelled Gulf Stream decreases near the Florida Straits (Fig. 11a-b). This is caused by a reduced strength of the North Brazil current leading to a reduced strength of the Caribbean and Loop currents. Furthermore, the strength of the South Equatorial Current is reduced and the strength of the Brazil current is increased. For the $0.5 \mathrm{~Sv}$ simulation, there is a change in the path of the North Atlantic current, from a northward-oriented component to a more eastward-oriented component, as can be clearly seen in the change in eddy kinetic energy (EKE) (Fig. 11d). As a consequence, less heat is transported northwards which cools the subpolar gyre and leads to the SSH decrease in this region through thermosteric contraction.The shift in the Gulf Stream path in the $0.5 \mathrm{HR}$ simulation redirects the eddy pathways to the eastern North Atlantic (region 3) causing the 
SSHP extremes to increase. In addition, eddies do not enter the subpolar gyre region (region 1) leading to longer return periods. The western North Atlantic (region 2) is slightly affected by the shift in the eddy field in the southern part of the region, where EKE decreases (Fig. 11d) leading to the decreased SSHP extreme for the return period of 100 months. For the $0.1 \mathrm{~Sv}$ HR simulation, a similar spatial structure change can be seen but of weaker amplitude (Fig. 11c). The change in the eddy pathways also causes the change in the extremes at the Azores Islands. Although the influence of eddies on SSH variability is strongly reduced near the ocean boundaries, it can still be of the order of several centimetres (Kanzow et al., 2009). Therefore, the change in extremes at the coast near Lisbon can also be connected to the change in the eddy pathways. In the LR simulations, these changes are not captured, as only large-scale changes in SSH can be represented.

In the HR model, a northward shift in the latitude of the Gulf Stream separation occurs after about 25 years (Fig. 12b). During the last decade of the $0.5 \mathrm{~Sv}$ model simulation, the position of the Gulf Stream separation stabilises at a level around $37^{\circ} \mathrm{N}$. The separation latitude in the control run remains in the interval $\left[35^{\circ} \mathrm{N}, 35.5^{\circ} \mathrm{N}\right]$. Although the latitude position of the Gulf Stream separation is already located too far north in the LR control simulation, a similar shift as in the HR simulation is also found (Fig. 12a). The shift is caused by the modification of the lateral density gradient over the Gulf Stream which decreases with time due to the freshening; i.e. the freshening to the north decreases the differences in dynamic height across the Gulf Stream. This leads to a change in the Rossby deformation radius affecting eddy formation and through rectification processes, to a weakening of the Gulf Stream core near the separation latitude (Fig. 12b). Consequently, the decrease of inertia causes a less sharp separation and a northward deflection of the jet.

\section{Summary, discussion and conclusion}

In this study, we investigated the SSH response after 50 years of freshwater input near Greenland in both strongly eddying (HR) and non-eddying (LR) ocean-only model (POP) configurations. The large freshwater perturbation amplitudes $(0.1$ and $0.5 \mathrm{~Sv}$ ) were here only used to cause the decrease in the AMOC. These values are unrealistic as a near-future scenario for freshwater input into the North Atlantic.

Sea level changes due to both freshwater input and ocean circulation changes are found in both model simulations. A comparison between LR and HR model versions shows that high spatial resolution is of major importance when investigating regional dynamic sea level changes in the North Atlantic. The detailed flow changes in the surface velocity field, in particular near the Gulf Stream region, in the HR simulation lead to large-scale SSH changes which are qualitatively
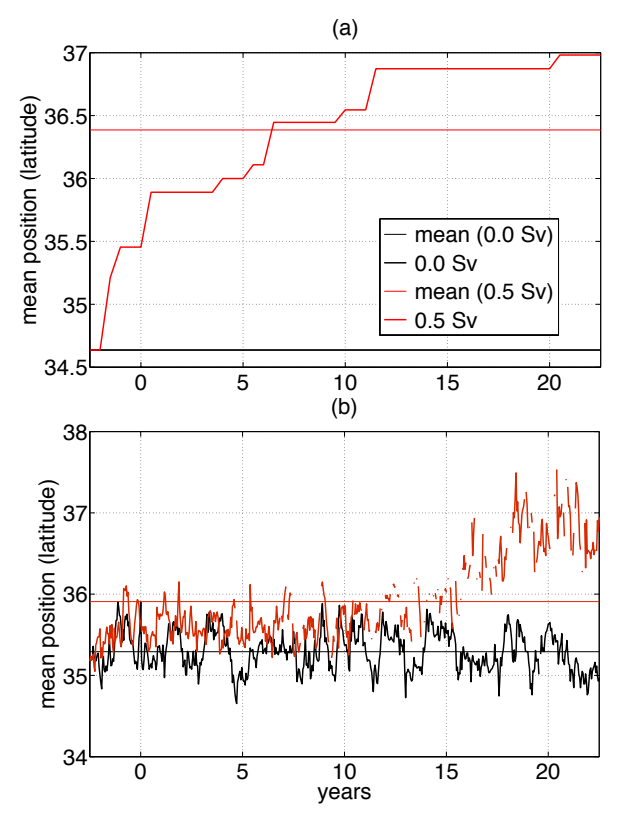

Figure 12. (a) Latitudinal position of the Gulf Stream separation from the LR control simulation (black) and the $0.5 \mathrm{~Sv}$ perturbation simulation (red). It is computed by identifying the path of the Gulf Stream from yearly mean sea surface height (SSH) data. Next the separation latitude is defined as the mean latitude position within the interval $\left[76^{\circ} \mathrm{W}, 70^{\circ} \mathrm{W}\right]$. The horizontal lines indicate the mean position of both time series. (b) Same as in (a) but for the HR $0.5 \mathrm{~Sv}$ simulation (monthly mean SSH data used).

very different from the LR model results, in particular in the subpolar gyre.

The differences between the $0.1 \mathrm{~Sv}$ and $0.5 \mathrm{~Sv}$ HR model responses are mostly quantitative. A freshwater inflow of $0.1 \mathrm{~Sv}$ shows similar response patterns in the velocity field and in SSH as in the $0.5 \mathrm{~Sv}$ results. The signal-to-noise ratio is, however, much smaller in the $0.1 \mathrm{~Sv}$ case. This is in good agreement with other studies, e.g. Kopp et al. (2010) and Brunnabend et al. (2012), which have shown that an increase in the amount of freshwater perturbation leads to an increased amplitude in SSH change while the pattern remains fairly similar.

The study by Firing and Merrifield (2004) showed that when investigating local extremes in sea level, eddies can further enhance short-term sea level extremes and that return times of these extremes decrease with rise in mean sea level. By focusing only on the monthly mean maxima and by filtering out the longer timescale effects, changes in shortterm extremes of local SSH due to flow changes were studied. For the $0.5 \mathrm{~Sv}$ HR simulation, a change in the spatial pattern of the eddy field especially near the coasts of Europe is found. This leads to an additional regional increase in SSH of several centimetres. Also, the return period of regional extremes that are caused by the changing eddy field is reduced in different coastal regions, causing more frequent extreme 
sea levels. The shift of the EKE distribution is not as pronounced in the $0.1 \mathrm{~Sv}$ as in the $0.5 \mathrm{~Sv}$ simulation and eddies have a smaller influence on SSH extremes in near-coastal regions during the investigated period of time.

In reality, the AMOC may be much more sensitive to freshwater perturbations than in the POP model considered here (Robson et al., 2014). The HR POP version is not in a multiple equilibrium regime (Den Toom et al., 2014) and hence the AMOC does not collapse to a different equilibrium state. When the AMOC is in a multiple equilibrium regime, it may actually decrease within a few decades (Hawkins et al., 2011), even under much smaller freshwater perturbations. In this case variations in eddy paths can provide an additional component of sea level change which can strongly affect regional and local extremes. So far this component has not been considered, as it is not represented in LR ocean-climate models, but in future scenarios of coastal sea level change, where the extreme scenario of AMOC changes is considered, it should be taken into account.

Acknowledgements. The project is supported by the Netherlands eScience Center (NLeSC) via the project eSALSA (An eScience Approach to determine future Sea-level chAnges). The simulations have been performed on the Huygens and Cartesius supercomputer at SURFsara (https://www.surfsara.nl) through the project SH243-13. We thank Leela Frankcombe for providing the scripts to compute the separation latitude of the Gulf Stream (Fig. 12). This work was partially funded by the Dutch national research program COMMIT.

Edited by: N. Wells

\section{References}

Antonov, J. I., Levitus, S., and Boyer, T. P.: Thermosteric sea level rise, 1955-2003, Geophys. Res. Lett., 32, L12602, doi:10.1029/2005GL023112, 2005.

Berge-Nguyen, M., Cazenave, A., Lombard, A., Liovel, W., Viarra, J., and Cretaux, J. F.: Reconstruction of past decades sea level using thermosteric sea level, tide gauge, satellite altimetry and ocean reanalysis data, Global Planet. Change, 62, 1-13, doi:10.1016/j.gloplacha.2007.11.007, 2008.

Bindoff, N. L., Willebrand, J., Artale, V., Cazenave, A., Gregory, J., Gulev, S., Hanawa, K., Le Quéréand, C., Levitus, S., Nojiri, Y., Shum, C. K., Talley, L. D., and Unnikrishnan, A.: Observations: Oceanic Climate Change and Sea Level, in: The Scientific Basis, Contribution of Working Group I to the Fourth Assessment Report of the Intergovernmental Panel on Climate Change, edited: by Solomon, S., Qin, D., Manning, M., Chen, Z., Marquis, M., Averyt, K. B., Tignor, M., and Miller, H. L., Cambridge University Press, Cambridge, New York, 2007.

Brunnabend, S.-E., Schröter, J., Timmermann, R., Rietbroek, R., and Kusche, J.: Modeled steric and mass-driven sea level change caused by Greenland Ice Sheet melting, J. Geodyn., 59-60, 219225, doi:10.1016/j.jog.2011.06.001, 2012.
Church, J. A. and White, N. J.: Sea-Level Rise from the Late 19th to the Early 21st Century, Surv. Geophys., 32, 585-602, doi:10.1007/s10712-011-9119-1, 2011.

Church, J. A., White, N. J., Aarup, T., Wilson, W. S., Woodworth, P. L., Domingues, C. M., Hunter, J. R., and Lambeck, K.: Understanding global sea levels: past, present and future, Sustain. Sci., 3, 9-22, doi:10.1007/s11625-008-0042-4, 2008.

Clark, J. A., Farrell, W. E., and Peltier, W. R.: Global Changes in Postglacial Sea Level: A Numerical Calculation, Quaternary Res., 9, 265-287, 1978.

Coles, S.: An Introduction to Statistical Modeling of Extreme Values, Springer-Verlag London Ltd, ISBN 1-85233-459-2, 2001.

Collins, W. D., Bitz, C., Blackmon, M. L., Bonan, G., Bretherton, C. S., Carton, J. A., Chang, P., Doney, S. C., Hack, J. J., Henderson, T. B., Kiehl, J. T., Large, W. G., McKenna, D. S., Santer, B. D., and Smith, R. D.: The Community Climate System Model Version 3 (CCSM3), J. Clim., 19, 2122-2143, doi:10.1175/JCLI3761.1, 2006.

Den Toom, M., Dijkstra, H. A., Weijer, W., Hecht, M. W., and Maltrud, M. E.: Sensitivity of a Strongly Eddying Global Ocean to North Atlantic Freshwater Perturbations, J. Phys. Oceanogr., 44, 464-481, 2014.

Farrell, W. E. and Clark, J. A.: On Postglacial Sea Level, Geophysi. J. Roy. Astr. S., 46, 647-667, doi:10.1111/j.1365246X.1976.tb01252.x, 1976.

Firing, Y. L. and Merrifield, M. A.: Extreme sea level events at Hawaii: Influence of mesoscale eddies, Geophys. Res. Lett., 31, L24306 doi:10.1029/2004GL021539, 2004.

Flückiger, J., Knutti, R., and White, J. W. C.: Oceanic processes as potential trigger and amplifying mechanisms for Heinrich events, Paleoceanography, 21, pA2014 doi:10.1029/2005PA001204, 2006.

Gerdes, R., Hurlin, W., and Griffies, S. M.: Sensitivity of a global ocean model to increased run-off from Greenland, Ocean Model., 12, doi:10.1016/j.ocemod.2005.08.003, 2006.

Greatbatch, R. J.: A note on the representation of steric sea level in models that conserve volume rather than mass, J. Geophys. Res., 99, 12767-12771, 1994.

Hawkins, E., Smith, R. S., Allison, L. C., Gregory, J. M., Woollings, T. J., Pohlmann, H., and De Cuevas, B.: Bistability of the Atlantic overturning circulation in a global climate model and links to ocean freshwater transport, Geophys. Res. Lett., 38, L10605, doi:10.1029/2011GL047208, 2011.

Hu, A., Meehl, G. A., Han, W., and Yin, J.: Effect of the potential melting of the Greenland Ice Sheet on the Meridional Overturning Circulation and global climate in the future, Deep-Sea Res. PT II, 58, 1914-1926, doi:10.1016/j.dsr2.2010.10.069, 2011.

Ishii, M., Kimoto, M., and Kaci, M.: Historical ocean subsurface temperature analysis with error estimates, Mon. Weather Rev., 131, 51-73, 2003.

Kanzow, T., Johnson, H. L., Marshall, D. P., Cunningham, S. A., Hirschi, J.-M., Bryden, H. L., and Johns, W. E.: Besinwide Integration Volume Transports in an Eddy-Filled Ocean, J. Phys. Oceanogr., 39, 3091-3110, doi:10.1175/2009JPO4185.1, 2009.

Kopp, R. E., Mitrovica, J. X., Griffies, S. M., Yin, J., Hay, C. C., and Stouffer, R. J.: The impact of Greenland melt on local sea levels: a partially coupled analysis of dynamic and static equilibrium effects in idealized water-hosing experiments, Clim. Change, 103, 619-625, doi:10.1007/s10584-010-9935-1, 2010. 
Landerer, F. W., Jungclaus, J. H., and Marotzke, J.: Regional Dynamic and Steric Sea Level Change in Response to the IPCC-A1B Scenario, J. Phys. Oceanogr., 37, 296-312, doi:10.1175/JPO3013.1, 2007.

Large, W. G. and Yeager, S. G.: Diurnal to decadal global forcing for ocean and sea-ice models; the datasets and flux climatologies, NCAR Technical Note TN 460 STR, http://www.clivar.org/ organization/wgomd/resources/core/core-i (last access: 8 October 2008), 2004.

Levermann, A., Griesel, A., Hofmann, M., Montoya, M., and Rahmstorf, S.: Dynamic sea level changes following changes in the thermohaline circulation, Clim. Dynam., 24, 347-354, doi:10.1007/s00382-004-0505-y, 2005.

Lorbacher, K., Dengg, J., and Biastoch, C. W. B.: Regional Patterns of Sea Level Change Related to Interannual Variability and Multidecadal Trends in the Atlantic Meridional Overturning Circulation, J. Clim., 23, 4243-4254, doi:10.1175/2010JCLI3341.1, 2010.

Lowe, J. A., Woodworth, P. L., Knutson, T., McDonald, R. E., McInnes, K. L., With, K., von Storch, H., Wolf, J., Swail, V., Bernier, N. B., Gulev, S., Horsburgh, K. J., Unnikrishnan, A. S., Hunter, J. R., and Wiese, R.: Past and Future Change in Extreme Sea Levels and Waves, in: Understanding Sea-Level Rise and Variability, edited by: Church, J. A., Woodworth, P. L., Aarup, T., and Wilson, W. S., 326-375, Wiley-Blackwell, UK, 2010.

Maltrud, M., Bryan, F., Hecht, M., Hunke, E., Ivanova, D., McClean, J., and Peacock, S.: Global Ocean Modeling in the Eddying Regime Using POP, CLIVAR Exchange, 44, 5-8, 2008.

Marcos, M., Tsimplis, M. N., and Shaw, A. G. P.: Sea level extremes in southern Europe, J. Geophys. Res., 114, C01007, doi:10.1029/2008JC004912, 2009.

Marshall, J., Adcroft, A., Hill, C., Perelman, L., and Heisey, C.: A finite-volume, incompressible Navier-stokes model for studies of the ocean on parallel computers, J. Geophys. Res., 102, 57535766, doi:10.1029/96JC02775, 1997.

Mernild, S. H., Liston, G. E., Hiemstra, C. A., and Christensen, J. H.: Greenland Ice Sheet Surface Mass-Balance Modeling in a 131-Yr Perspective, 1950-2080, Journal of Hydrometeorol., 11, 3-25, doi:10.1175/2009JHM1140.1, 2010.

Merrifield, M. A., Genz, A. S., Kontoes, C. P., and Marra, J. J.: Annual maximum water levels from tide gauges: Contribution factors and geographic patterns, J. Geophys. Res.-Ocean., 118, 2535-2546, doi:10.1002/jgrc.20173, 2013.

Mitrovica, J. X., Tamisiea, M. E., Davis, J. L., and Milne, G. A.: Recent mass balance of polar ice sheets inferred from patterns of global sea-level change, Nature, 409, 1026-1029, 2001.

Mitrovica, J. X., Gomez, N., Morrow, E., Hay, C., Latychey, K., and Tamisiea, M. E.: On the robustness of predictions of sea level fingerprints, Geophys. J. Int., 197, 729-742, doi:10.1111/j.1365246X.2011.05090.x, 2011.

Rignot, E. and Kanagaratnam, P.: Changes in the velocity structure of the Greenland Ice Sheet, Science, 311, 986-990, doi:10.1126/science.1121381, 2006.

Rio, M.-H. and Hernandez, F.: A Mean Dynamic Topography computed over the world ocean from altimetry, in-situ measurements and a geoid model, J. Geophysi. Res., 109, C12032 doi:10.1029/2003JC002226, 2004.
Robson, J., Hodson, D., Hawkins, E., and Sutton, R.: Atlantic overturning in decline?, Nature Geoscience, 7, 2-3, doi:10.1038/ngeo2050, 2014.

Sidorenko, D., Wang, Q., Danilov, S., and Schröter, J.: FESOM under coordinated ocean-ice reference experiment forcing, Ocean Dynam., 61, 881-890, doi:10.1007/s10236-011-0406-7, 2011.

Srokosz, M., Baringer, M., Bryden, H., Cunningham, S., Delworth, T., Lozier, S., Marotzke, J., and Sutton, R.: Past, Present, and Future Changes in the Atlantic Meridional Overturning Circulation, Bull. Amer. Meteor. Soc., 93, 1663-1676, doi:10.1175/BAMSD-11-00151.1, 2012.

Stammer, D.: Response of the global ocean to Greenland and Antarctic ice melting, J. Geophysi. Res., 113, C06022, doi:10.1029/2006JC004079, 2008.

Stammer, D., Agarwal, N., Herrmann, P., Köhl, A., and Mechoso, C. R.: Response of a Coupled Ocean-Atmosphere Model to Greenland Ice Melting, Surv. Geophys., 32, 621-642, doi:10.1007/s10712-011-9142-2, 2011.

Stouffer, R. J., Yin, J., Gregory, J. M., Dixon, K. W., Spelman, M. J., Hurlin, W., Weaver, A. J., Eby, M., Flato, G. M., Hasumi, H., Hu, A., Jungclaus, J. H., Kamenkovich, I. V., Levermann, A., Montoya, M., Murakami, S., Nawrath, S., Oka, A., Peltier, W. R., Robitaille, D. Y., Sokolov, A., Vettoretti, G., and Waber, S. L.: Investigating the Causes of the Response of the Thermohaline Circulation to Past and Future Climate Changes, J. Clim., 19, doi:10.1175/JCLI3689.1, 2006.

Volkov, D. L., Hendrik, M., and van Aken, H. W.: Annual and inter annual variability of sea level in the northern North Atlantic Ocean, J. Geophys. Res., 108, 3204, doi:10.1029/2002JC001459, 2003.

Wang, X., Wang, Q., Sidorenko, D., Danilov, S., Schröter, J., and Jung, T.: Long term ocean simulations in FESOM: Evaluation and application in studying the impact of Greenland Ice Sheet melting, Ocean Dynam., 62, 1477-1486, doi:10.1007/s10236012-0572-2, 2012.

Weijer, W., Maltrud, M. E., Hecht, M. W., Dijkstra, H. A., and Kliphuis, M. A.: Response of the Atlantic Ocean circulation to Greenland Ice Sheet melting in a strongly-eddying ocean model, Geophys. Res. Lett., 39, L09606, doi:10.1029/2012GL051611, 2012.

Woodworth, P. L., Gehrels, W. R., and Nerem, R. S.: Nineteenth and twentieth century changes in sea level, Oceanography, 24, 80-93, doi:10.5670/oceanog.2011.29, 2011a.

Woodworth, P. L., Menéndez, M., and Gehrels, W. R.: Evidence for Century-Timescale Acceleration in Mean Sea Levels and for Recent Changes in Extreme Sea Levels, Surv. Geophys., 32, 603618, doi:10.1007/s10712-011-9112-8, 2011b.

Yin, J., Schlesinger, M. E., and Stouffer, R. J.: Model projections of rapid sea-level rise on the northeast coast of the United States, Nature Geoscience, 2, 262-266, doi:10.1038/NGEO0462, 2009. 